\title{
Cue-Induced Craving Increases Impulsivity via Changes in Striatal Value Signals in Problem Gamblers
}

\author{
Stephan F. Miedl, ${ }^{1,2}$ Christian Büchel, ${ }^{1,3}$ and Jan Peters ${ }^{1,4}$ \\ ${ }^{1}$ Department of Systems Neuroscience, University Medical Center Hamburg-Eppendorf, 20246 Hamburg, Germany, ${ }^{2}$ Department of Clinical Psychology, \\ Psychotherapy and Health Psychology, Institute of Psychology, University of Salzburg, 5020 Salzburg, Austria, ${ }^{3}$ Department of Psychology, Stanford \\ University, Stanford, California 94305, and ${ }^{4}$ Helen Wills Neuroscience Institute, University of California, Berkeley, California 94720
}

Impulsive behavior such as steep temporal discounting is a hallmark of addiction and is associated with relapse. In pathological gamblers, discounting may be further increased by the presence of gambling-related cues in the environment, but the extent to which the gambling relatedness of task settings affects reward responses in gambling addiction is debated. In the present study, human problem gamblers made choices between immediate rewards and individually tailored larger-but-later rewards while visual gambling-related scenes were presented in the background. $N=17$ participants were scanned using fMRI, whereas $N=5$ additional participants completed a behavioral version of the task. Postscan craving ratings were acquired for each image, and behavioral and neuroimaging data were analyzed separately for high- and low-craving trials (median split analysis). Discounting was steeper for high versus low craving trials. Neuroimaging revealed a positive correlation with model-based subjective value in midbrain and striatum in low-craving trials that was reversed in high-craving trials. These findings reveal a modulation of striatal reward responses in gamblers by addiction-related cues, and highlight a potentially important mechanism that may contribute to relapse. Cue-induced changes in striatal delayed reward signals may lead to increased discounting of future rewards, which might in turn affect the likelihood of relapse.

Key words: addiction; gambling; reward

\section{Introduction}

Pathological gambling shares many symptoms with substancebased addictions, such as impaired self-control, craving before gambling, and continuing gambling despite negative consequences (Potenza, 2008), and is categorized as a behavioral addiction in the Diagnostic and Statistical Manual of Mental Disorders 5 (DSM-5). Pathological gamblers show increased discounting of delayed monetary rewards (Petry, 2001b; Dixon et al., 2003; Miedl et al., 2012) similar to substance addicts such as alcoholics (Petry, 2001a), opioid-abusers (Kirby et al., 1999), cocaine dependents (Kirby and Petry, 2004), and smokers (Johnson et al., 2007; Peters et al., 2011), suggesting that temporal discounting might be a basic trait marker of addictive behavior (Bickel et al., 2014). Temporal discounting in healthy subjects is increased in the presence of appetitive pavlovian stimuli (Wilson and Daly, 2004; Li, 2008; Kim and Zauberman, 2013). Similar effects of gambling context occur in problem gamblers (Dixon et

Received Nov. 29, 2013; revised Jan. 30, 2014; accepted Feb. 17, 2014.

Author contributions: S.F.M., C.B., and J.P. designed research; S.F.M. performed research; J.P. contributed unpublished reagents/analytic tools; S.F.M. and J.P. analyzed data; S.F.M., C.B., and J.P. wrote the paper.

C.B. is supported by the Deutsche Forschungsgemeinschaft (DFG; SFB TRR58 and SFB 936) and ERC (2010AdG_20100407). J.P. is supported by the DFG (PE1627/3-1).

The authors declare no competing financial interests.

Correspondence should be addressed to Stephan F. Miedl, Department of Clinical Psychology, Psychotherapy and Health Psychology, Institute of Psychology, University of Salzburg, 5020 Salzburg, Austria. E-mail: stephan.miedl@sbg.ac.at.

DOI:10.1523/JNEUROSCI.5020-13.2014

Copyright $\odot 2014$ the authors $\quad 0270-6474 / 14 / 344750-06 \$ 15.00 / 0$ al., 2006), and such processes might have implications for cueinduced relapse.

Both striatal hyperactivation and hypoactivation have been reported in pathological gambling and addiction more generally (Balodis et al., 2012; Leyton and Vezina, 2012; van Holst et al., 2012; Clark and Limbrick-Oldfield, 2013). It was proposed that when familiar addiction-related cues are present striatal activation is enhanced; when the cues are absent, it is blunted, at least when absolute activation levels are concerned (Leyton and Vezina, 2013), but it is unclear how such cues might affect parametric reward representations (Miedl et al., 2012).

The present study examined striatal reward responsivity and cue-induced changes in impulsivity in gamblers. We hypothesized that gamblers would discount steeper in the presence of highly craving-inducing images (Dixon et al., 2006). Given that reward values are represented in ventral striatum (VS; Peters and Büchel, 2010b; Clithero and Rangel, 2013) and that addictionrelated cues increase craving via striatal dopamine (DA) release (Volkow et al., 2006), we hypothesized gambling cues to exert their influence on decision making by modulating striatal reward signals.

\section{Materials and Methods}

Participants. In total, $n=17$ male right-handed (Oldfield, 1971) slotmachine gamblers participated in the fMRI study, and $N=5$ additional subjects completed a behavioral version of the task without neuroimaging. No participant reported a history of regular drug use, and none were currently using medication. No active Axis I disorders were present apart from depression in six problem gamblers (Beck et al., 1961). All gamblers 
Table 1. Demographic data for fMRI and behavioral subjects (mean $\pm \mathrm{SE}$ )

\begin{tabular}{lcc}
\hline & $\mathrm{fMRI}(N=17)$ & Behavioral $(N=5)$ \\
\hline Male/female & $17 / 0$ & $5 / 0$ \\
Age & $30.24 \pm 3.00$ & $36.2 \pm 2.44$ \\
Fagerström & $3.12 \pm 0.71$ & $4.20 \pm 1.11$ \\
Alcoholic drinks/week & 0.41 (range: $0-2)$ & 0.20 (range: $0-1)$ \\
DSM & $6.18 \pm 0.51$ & $8.40 \pm 0.68$ \\
KFG & $29.88 \pm 2.23$ & $39.20 \pm 6.77$ \\
SOGS & $10.75 \pm 0.92$ & $12.20 \pm 2.13$ \\
Income/month in $€$ & $1319.40 \pm 185.98$ & $1696 \pm 465.21$ \\
Ratio lost/income & $0.83 \pm 0.29$ & $1.01 \pm 0.72$ \\
BDI & $14.12 \pm 2.35$ & $12.4 \pm 4.70$ \\
\hline
\end{tabular}

met at least three DSM-IV criteria (3 participants had a score of 3 or 4 points; 19 scored $\geq 5$ points). In addition, all gamblers completed the Kurzfragebogen zum Glücksspielverhalten (KFG; Petry, 1996) and the South Oaks Gambling Screen (SOGS; Lesieur and Blume, 1987).

Twelve of seventeen MRI participants were current smokers based on the Fagerström Test of Nicotine Dependence (Heatherton et al., 1991; see Table 1), and they were allowed to smoke freely before scanning (Miedl et al., 2012) to avoid effects of acute withdrawal. Alcohol use was low in the MRI sample, with 11 of 17 participants reporting to be abstinent (see Table 1).

Behavioral pretest. Participants completed a behavioral testing session $\sim 2 \mathrm{~h}$ before fMRI that included a short adaptive temporal discounting task (Peters and Büchel, 2009) to estimate the discount rate. Based on the pretest, subject-specific trials for the fMRI experiment were created (Peters and Büchel, 2009, 2010a; Miedl et al., 2012).

Visual gambling cues. During fMRI (see below) visual gambling cues were shown while participants performed a temporal discounting task. Pictures were collected from the Internet $(n=64$ images in total, each image was shown three times) and consisted of pictures of slot machines and indoor gambling facilities. Images were classified into high- and low-craving conditions based on postscan craving ratings (median split, $0-100$ visual analog scale). Valence and arousal ratings were additionally collected to confirm the validity of the craving ratings (i.e., more positive valence and greater arousal for high vs low craving). Rating questions were phrased as follows. Craving: How much do you feel like gambling when you see this image? [0: not at all . .., 100: very strongly]. Valence: How do you feel when you see this image? [ -50 : very negative .., 0 : neutral ..., 50: very positive]. Arousal: How aroused are you when you see this image? [0: not at all ..., 100: very strongly].

Many studies of cue reactivity in addiction use addiction-related cues and control cues (Potenza et al., 2003; Heinz et al., 2004). We took a different approach for two reasons. First, it is nearly impossible to perfectly match gambling-related and neutral cues such that they only differ in terms of gambling relatedness, but not in other features. Second, extensive pretesting revealed a considerable heterogeneity in craving induced by different gambling cues in different patients. Our design exploited this heterogeneity, while avoiding lower level confounds between conditions.

fMRI task. The task was a modification of a previous task (Peters and Büchel, 2009; Miedl et al., 2012) where participants made choices between a fixed immediate reward of $€ 20.0$ and larger delayed rewards while viewing gambling scenes in the background (Figure 1). Individual offers were calculated for each participant (see above) and participants completed three sessions ( $\sim 15 \mathrm{~min}$ and 64 trials each). The 64 gambling images were randomly assigned to the trials and were shown once per session. Participants were told that one of their choices would randomly be selected and that they would receive the chosen reward amount via a bank transfer or in cash. The average amount participants received was $€ 31.7$ (range, €20.0-70.9).

Computational modeling. Behavioral data were analyzed applying maximum-likelihood estimation using optimization procedures implemented in MATLAB (fminsearch). We used the softmax choice function as follows:

$$
P\left(o_{i}\right)=\frac{\exp \left(s v_{o i} / \beta\right)}{\exp \left(s v_{o 1} / \beta\right)+\exp \left(s v_{o 2} / \beta\right)}
$$

to estimate the probability of choosing the actually selected option $\left(o_{i}\right)$ given the subjective values of the available options: $s v_{o 1}$ and $s v_{o 2}$ (based on Eq. 2). $\beta$ is a free parameter modeling the inverse steepness of the sigmoid (choice stochasticity). We applied the hyperbolic discounting model (Mazur and Coe, 1987) as follows:

$$
S V=\frac{A}{(1+k D)}
$$

where $A$ is the objective reward amount, $D$ is delay, and $k$ is a subjectspecific discount rate.

We then minimized the log-likelihood (LL) of the choice probabilities, summing across trials, given a particular set of model parameters $\theta$ :

$$
L L=\sum_{t} \log \left(P o_{t} \mid \theta\right)
$$

to obtain the best-fitting parameter estimates for each subject and condition $(k$ and $\beta$ ), which were used to compute subjective values for each trial. Model fit was quantified using the Bayesian Information Criterion (BIC; Schwarz, 1978).

fMRI data acquisition. MRI data were acquired on a $3 \mathrm{~T}$ system (Siemens TIM-TRIO) using a 32-channel head coil. Five-hundred volumes, aligned to the line connecting anterior and posterior commissures, were acquired for each session, and the first five volumes were discarded to allow for the BOLD signal to stabilize. Each volume consisted of 40 slices with a voxel size of $2 \times 2 \times 2$ and $1 \mathrm{~mm}$ gap (repetition time: $2.38 \mathrm{~s}$; echo-time: $25 \mathrm{~ms}$ ). An additional magnetization-prepared rapidacquisition gradient echo structural image was acquired for anatomical overlay.

fMRI data analysis. Data preprocessing and analysis was performed using SPM8 (Wellcome Department of Cognitive Neurology, London, UK). Functional images were slice time corrected to the onset of the middle slice and spatially realigned using a six-parameter affine transformation. The high-resolution T1 image was then coregistered to the functional images and segmented into gray matter, white matter, and CSF. Functional images were spatially normalized to Montreal Neurological Institute space using the normalization parameters obtained from the segmentation procedure and subsequently smoothed with a Gaussian kernel of $8 \mathrm{~mm}$ full-width at half-maximum.

A first-level model was constructed on the single subject data using the following regressors: the presentation of delayed options was modeled by convolving the event train of stimulus onsets with the canonical hemodynamic response function separately for each session. For each event, a primary parametric regressor was included coding for the subjective value of the decision option in each trial. Error trials and button presses were modeled separately. To deal with residual variance caused by subject movement, the realignment parameters were included as additional regressors at the first level.

For each participant, the following contrast images were computed: (1) delayed reward onset for all trials, (2) delayed reward onset for lowcraving $>$ high-craving situations, (3) delayed reward onset parametrically modulated by the subjective value across conditions, (4) delayed reward onset parametrically modulated by the subjective value (low craving $>$ high craving), and (5) delayed reward onset parametrically modulated by craving score.

We then entered these contrast images into second-level random effects models using one-sample $t$ tests, including covariates of depression [Beck Depression Inventory score (BDI)] and gambling severity (KFG). For all analyses, the threshold was set to $p<0.05$ corrected for multiple comparisons (based on the FWE) using reduced search volumes [small volume correction (SVC)]. Spherical search volumes were used centered at peak coordinates from previous studies. We used a $10 \mathrm{~mm}$ sphere for the VS (O'Doherty et al., 2004) and a $6 \mathrm{~mm}$ sphere for the midbrain/ substantia nigra (Schott et al., 2006). Activations are displayed projected onto the mean structural scan across participants. 


\section{Results}

\section{Behavioral data}

Gambling images were classified into high and low craving based on postscan craving ratings (median split). Additional valence and arousal ratings were collected (Fig. 2) to confirm the validity of the craving ratings. High-craving images were rated as more positive $\left(t_{(32)}=6.71, p<\right.$ 0.001 ; Fig. $2 B)$ and more arousing $\left(t_{(32)}=\right.$ $6.88, p<0.001$; Fig. $2 C$ ), and those ratings were highly correlated within subjects (mean $r$ [range] valence arousal $=0.72[0.21-0.96]$, arousal craving $=0.78[0.48-0.97]$, valence craving $=0.68[0.12-0.97])$.

We then fit separate temporal discounting models to the choice data from high-craving and low-craving trials to obtain condition-specific model parameters $k$ and $\beta$. Across all 22 participants $(n=5$ behavior only, $n=17$ behavior + fMRI) $k$ parameters were significantly higher in high versus low craving (median $k$ : high craving $=0.11$, low craving $=0.09, z=-2.52$, $p=0.012$, two-tailed; Wilcoxon signed rank test due to nonnormally distributed data). A similar trend was seen when restricting the analysis to the behavioral data from the fMRI participants $(z=-1.78, p=0.076$, two-tailed; Fig. $2 D)$. In contrast, no differences between conditions were observed for reaction times $\left(t_{(32)}=0.21, p=0.84\right)$ and $\beta\left(t_{(32)}=0.099, p=0.92\right)$, and the fit of the behavioral model in terms of BIC was similar between conditions $\left(t_{(32)}=0.08, p=0.94\right)$.

\section{fMRI results}

Brain activity during trial onset

There was no difference in overall activation levels between conditions (i.e., without parametric modulation) at $p<0.001$ uncorrected.

\section{Neural craving representations}

Including subjective craving ratings as a parametric modulator revealed a positive correlation with activity in right middle temporal gyrus ( $x, y, z$ coordinates: $52,-68,8, z$-value $=3.72)$ and right fusiform gyrus $(46,-44,-22, z$-value $=3.35)$. Valence and arousal ratings were highly correlated with craving (see above), and were thus not analyzed separately.

\section{Model-based subjective value}

No brain regions showed a positive correlation with subjective value across high and low craving at $p<0.001$. Testing for brain areas showing a more positive correlation with value in low versus high craving revealed activity in the midbrain $(12,-18,-22$, $z$-value $=3.57, \mathrm{p}_{\mathrm{SVC}}=0.006$; Fig. 3 ) and bilateral VS (left: $-16,14,-10, z$-value $=3.36, \mathrm{p}_{\mathrm{SVC}}=0.019 ;$ right: $12,16,-4$, $z$-value $=2.78, \mathrm{p}_{\mathrm{SvC}}=0.079$; Fig. 3 ). The reverse contrast showed no significant effects at $p<0.001$ uncorrected. We extracted $\beta$ estimates from these peaks to examine the directionality of the effects. As can be seen from Figure 3, the effects were primarily driven by the presence of a positive value correlation under low craving, which was reversed under high craving.

We performed a number of control analyses. First we examined an additional model that included smoking severity (Fagerström scores) as an additional covariate. This did not alter the pattern of results (midbrain: $10,-18,-18, z$-value $=3.4, \mathrm{p}_{\mathrm{SVC}}=$ 0.005; left VS: $-14,16,-10, z$-value $=3.26$, $\mathrm{p}_{\mathrm{svC}}=0.026$; right VS: $12,16,-4, z$-value $\left.=2.68, \mathrm{p}_{\mathrm{SvC}}=0.094\right)$. Second, we restricted the analysis to gamblers with DSM IV-scores $\geq 5$ (i.e., problem gam- blers were excluded). This did not alter the pattern of results (midbrain: $\mathrm{p}_{\mathrm{SVC}}=0.021$; left VS: $\mathrm{p}_{\mathrm{SVC}}=0.038$; right VS: $\mathrm{p}_{\mathrm{SVC}}=$ 0.079). Finally, subjects discounted steeper in the high-craving condition, and this may have affected the neural results. We therefore fitted a single $k$ parameter across low- and high-craving trials for each participant, and calculated model-based values using these canonical $k$ parameters. Again, the differences between low and high craving remained significant (midbrain: $12,-16,-18, z$-value $=3.58, \mathrm{p}_{\mathrm{SVC}}=0.003$; left VS: $-14,16,-10$, $z$-value $=3.56, \mathrm{p}_{\mathrm{SVC}}=0.011$; right VS: $8,6,-18, z$-value $=2.84$, $\left.\mathrm{p}_{\mathrm{SVC}}=0.065\right)$.

\section{Discussion}

We examined the context dependency of neuronal reward representations in problem gamblers using model-based fMRI and a temporal discounting task that included gambling-related cues. Gamblers discounted delayed rewards more steeply in the presence of high-craving gambling cues (Dixon et al., 2006). Neuroimaging results revealed a positive correlation with value in low craving in midbrain and bilateral VS that was reversed in high craving.

This observation extends previous results of neural value processing in gamblers versus healthy controls (Miedl et al., 2012). We previously reported reduced value coding during probability discounting and elevated value coding during temporal discounting in gamblers. We speculated that temporal discounting might represent a more neutral (gambling-unrelated) task, whereas probability discounting might be more gambling related due to high familiarity of gamblers with risky choices. The present observation of reversed striatal and midbrain value signals during high-craving trials supports this previous interpretation. That being said, we acknowledge that whether probabilistic trials in that study can really be considered to constitute "gamblingrelated" stimuli remains an open question, as all trials involved simple text displays. In contrast, the present study used rich visual gambling cues, therefore, providing a more direct test of the role of craving and gambling-related cues.

One may argue that a fully crossed design examining both cue and task effects (temporal vs probability discounting) would have been more informative. However, this was not feasible due to the trial numbers required for accurate behavioral modeling, and we therefore focused on temporal discounting, which was previously shown to be under contextual modulatory control in gamblers (Dixon et al., 2006). In combination with our previous study, our data suggest that preserved value signals during delay discounting in gamblers (Miedl et al., 2012) are reduced in the presence of high-craving relative to low-craving inducing gambling cues.

These findings bear direct relevance to an ongoing discussion in addiction neuroscience. Both hyperactivation and hypoactivation in striatal regions have been observed in pathological gamblers (Reuter et al., 2005; Chase and Clark, 2010; Balodis et al., 
A

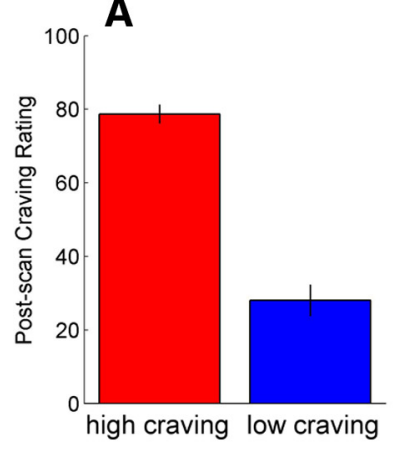

B

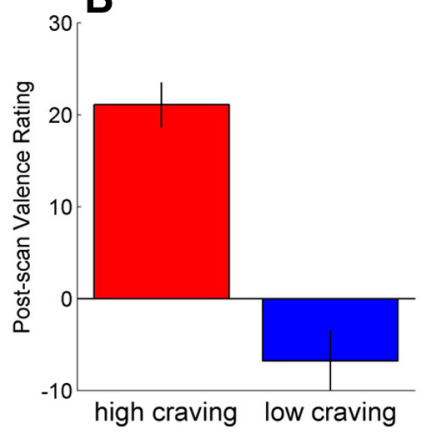

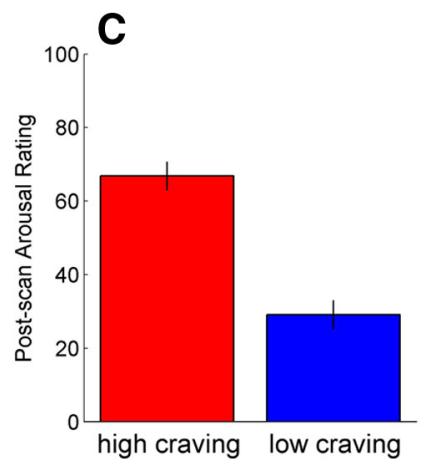

D

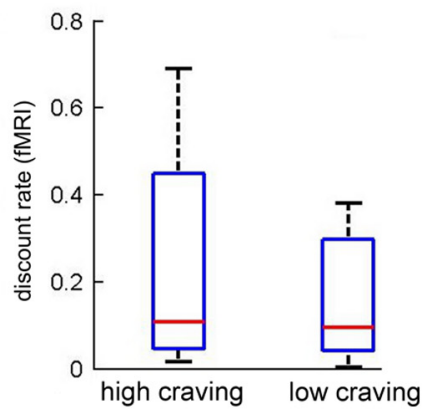

Figure 2. Behavioral data from fMRI participants $(N=17)$. Post scan ratings for craving $(\boldsymbol{A})$, valence $(\boldsymbol{B})$, and arousal $(\boldsymbol{C})$ for high- and low-craving trials. Trials were classified according to craving ratings, but differed also on valence and arousal. Discount rates ( $\boldsymbol{D}$, box plot) where increased in high versus low craving (see Results). Error bars in $\boldsymbol{A}-\boldsymbol{C}$ indicate $\pm \mathbf{S E M}$.

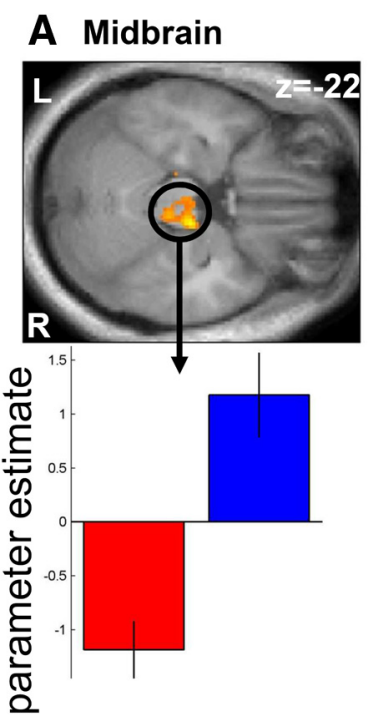

low-craving
B Ventral Striatum

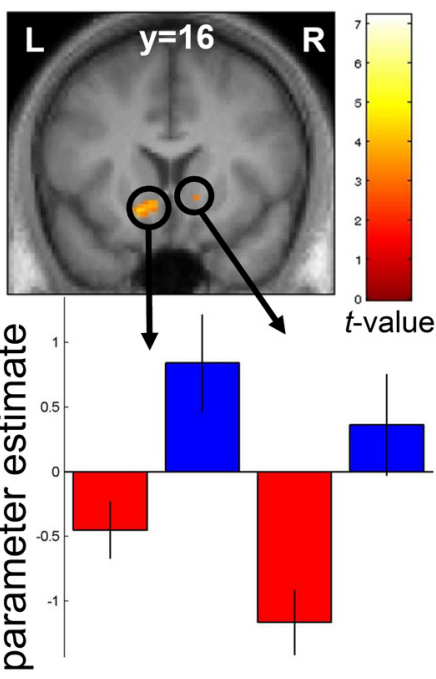

high-craving
Figure 3. Regions that showed a more positive correlation with subjective value in the low-craving compared with the high-craving situation. $\boldsymbol{A}$, Midbrain $[12,-18,-22]$. $\boldsymbol{B}$, VS: L, $[-16,14,-10] ; \mathrm{R},[12,16,-4]$ (display threshold, $p<0.005$, uncorrected). Error bars indicate $\pm S E M$. $L$, left; $R$, right.

2012; Leyton and Vezina, 2012; van Holst et al., 2012; Clark and Limbrick-Oldfield, 2013; Sescousse et al., 2013) and addictive disorders more generally (Leyton and Vezina, 2013). It has been suggested that the presence of addiction-related cues might boost reward responses, whereas their absence might attenuate these signals (Leyton and Vezina, 2013), at least with respect to absolute activation levels. Our data inform this debate by showing that the (parametric) neural representation of reward value during temporal discounting in gamblers is indeed modulated by the degree of craving induced by gambling-related cues. An open question is why the modulation in high-craving took this particular form and was at least in part driven by a negative effect, rather than showing a reduced positive or null effect. That being said, it should be noted that the within-condition effects were also somewhat less robust, and showed more variability between regions (see, e.g., left vs right VS), which makes it difficult to draw firm conclusions from these findings.

Behaviorally, the modulatory influence of appetitive visual gambling cues on temporal discounting resembles previous effects of appetitive pavlovian stimuli on discounting behavior in healthy controls (Wilson and Daly, 2004; Li, 2008; Kim and
Zauberman, 2013). It is therefore possible that the observed effects are not specific to the nature of the cues or to the particular patient group studied here, and subjectively appetitive stimuli might generally enhance impulsive responding. However, the impact of such effects may be particularly problematic for patients who are likely to be more impulsive to begin with and who may be driven to relapse due to exposure to such cues.

Drug-related cues induce craving via DA release in the striatum (Volkow et al., 2006). This increase in DA might in turn impair the ability of the striatum to robustly represent values of delayed rewards, which might increase impulsive responding. Interactions between tonic and phasic DA responses that might account for such a pattern have been previously described (Bilder et al., 2004). These effects might thus resemble pavlovianinstrumental transfer (PIT), a classical account of pavlovian influences on instrumental responding (Balleine and O'Doherty, 2010), which is similarly mediated by DA (Dickinson et al., 2000; Lex and Hauber, 2008; Ostlund and Maidment, 2012; Beierholm et al., 2013). However, this interpretation is weakened by the lack of an overall difference in dopaminergic region activation between conditions, which might be expected to track differences in DA release (Schott et al., 2008), On the other hand, the present task contrasted degrees of craving, rather than craving versus no craving, and might thus not be sensitive enough to capture subtle overall activation differences. Therefore, future studies are required to more directly assess the role that DA plays in pavlovian modulations of discounting behavior, and the extent to which these effects may share features with processes such as PIT.

A potential alternative mechanism underlying increased discounting during high craving might be an attentional bias to addiction-related cues (Robbins and Ehrman, 2004; Field and Cox, 2008). Such effects also depend on DA neurotransmission (Franken et al., 2004), and might thus also be compatible with the observed striatal effects. However, both reaction times and choice consistency $(\beta)$ were similar for high- and low-craving trials. This argues against a simple distraction account of the cue effects, which would be expected to increase reaction times and/or decrease consistency.

The present study focused on gambling-related appetitive cues in problem gamblers and did not include a comparison group. Our data thus cannot address the issue of whether addiction in general alters susceptibility to appetitive cues. Future studies using different classes of appetitive cues in both addicts and controls are required to address this interesting issue.

Our results support the idea that the presence of addictionrelated cues in the environment modulates striatal value signals 
in addicts (Leyton and Vezina, 2013) and can increase impulsive behavior (Dixon et al., 2006). While the potential role of DA in mediating these effects remains to be directly examined (Volkow et al., 2006), our findings highlight a potentially important mechanism underlying cue-induced relapse in addiction: cue-induced changes in striatal value coding may lead to increased future reward discounting, which may in turn affect the likelihood of relapse (Sheffer et al., 2012).

\section{References}

Balleine BW, O'Doherty JP (2010) Human and rodent homologies in action control: corticostriatal determinants of goal-directed and habitual action. Neuropsychopharmacology 35:48-69. CrossRef Medline

Balodis IM, Kober H, Worhunsky PD, Stevens MC, Pearlson GD, Potenza MN (2012) Attending to striatal ups and downs in addictions. Biol Psychiatry 72:e25-e26. CrossRef Medline

Beck AT, Ward CH, Mendelson M, Mock J, Erbaugh J (1961) An inventory for measuring depression. Arch Gen Psychiatry 4:561-571. CrossRef Medline

Beierholm U, Guitart-Masip M, Economides M, Chowdhury R, Düzel E, Dolan R, Dayan P (2013) Dopamine modulates reward-related vigor. Neuropsychopharmacology 38:1495-1503. CrossRef Medline

Bickel WK, Koffarnus MN, Moody L, Wilson AG (2014) The behavioraland neuro-economic process of temporal discounting: a candidate behavioral marker of addiction. Neuropharmacology 76:518-527. CrossRef Medline

Bilder RM, Volavka J, Lachman HM, Grace AA (2004) The catechol-Omethyltransferase polymorphism: relations to the tonic-phasic dopamine hypothesis and neuropsychiatric phenotypes. Neuropsychopharmacology 29:1943-1961. CrossRef Medline

Chase HW, Clark L (2010) Gambling severity predicts midbrain response to near-miss outcomes. J Neurosci 30:6180-6187. CrossRef Medline

Clark L, Limbrick-Oldfield EH (2013) Disordered gambling: a behavioral addiction. Curr Opin Neurobiol 23:655-659. CrossRef Medline

Clithero JA, Rangel A (2013) Informatic parcellation of the network involved in the computation of subjective value. Soc Cogn Affect Neurosci. Advance online publication. Retrieved Aug. 21, 2013. doi:10.1093/scan/ nst106. CrossRef

Dickinson A, Smith J, Mirenowicz J (2000) Dissociation of Pavlovian and instrumental incentive learning under dopamine antagonists. Behav Neurosci 114:468-483. CrossRef Medline

Dixon MR, Marley J, Jacobs EA (2003) Delay discounting by pathological gamblers. J Appl Behav Anal 36:449-458. CrossRef Medline

Dixon MR, Jacobs EA, Sanders S (2006) Contextual control of delay discounting by pathological gamblers. J Appl Behav Anal 39:413-422. CrossRef Medline

Field M, Cox WM (2008) Attentional bias in addictive behaviors: a review of its development, causes, and consequences. Drug Alcohol Depend 97:120. CrossRef Medline

Franken IH, Hendriks VM, Stam CJ, Van den Brink W (2004) A role for dopamine in the processing of drug cues in heroin dependent patients. Eur Neuropsychopharmacol 14:503-508. CrossRef Medline

Heatherton TF, Kozlowski LT, Frecker RC, Fagerström K-O (1991) The Fagerström Test for Nicotine Dependence: a revision of the Fagerstrom Tolerance Questionnaire. Br J Addict 86:1119-1127. CrossRef Medline

Heinz A, Siessmeier T, Wrase J, Hermann D, Klein S, Grüsser SM, Flor H, Braus DF, Buchholz HG, Gründer G, Schreckenberger M, Smolka MN, Rösch F, Mann K, Bartenstein P (2004) Correlation between dopamine $\mathrm{D}(2)$ receptors in the ventral striatum and central processing of alcohol cues and craving. Am J Psychiatry 161:1783-1789. CrossRef Medline

Johnson MW, Bickel WK, Baker F (2007) Moderate drug use and delay discounting: a comparison of heavy, light, and never smokers. Exp Clin Psychopharmacol 15:187-194. CrossRef Medline

Kim BK, Zauberman G (2013) Can Victoria's Secret change the future? A subjective time perception account of sexual-cue effects on impatience. J Exp Psychol Gen 142:328-335. CrossRef Medline

Kirby KN, Petry NM (2004) Heroin and cocaine abusers have higher discount rates for delayed rewards than alcoholics or non-drug-using controls. Addiction 99:461-471. CrossRef Medline

Kirby KN, Petry NM, Bickel WK (1999) Heroin addicts have higher dis- count rates for delayed rewards than non-drug-using controls. J Exp Psychol Gen 128:78-87. CrossRef Medline

Lesieur HR, Blume SB (1987) The South Oaks Gambling Screen (SOGS): a new instrument for the identification of pathological gamblers. Am J Psychiatry 144:1184-1188. Medline

Lex A, Hauber W (2008) Dopamine D1 and D2 receptors in the nucleus accumbens core and shell mediate Pavlovian-instrumental transfer. Learn Mem 15:483-491. CrossRef Medline

Leyton M, Vezina P (2012) On cue: striatal ups and downs in addictions. Biol Psychiatry 72:e21-e22. CrossRef Medline

Leyton M, Vezina P (2013) Striatal ups and downs: their roles in vulnerability to addictions in humans. Neurosci Biobehav Rev 37:1999-2014. CrossRef Medline

Li X (2008) Effects of appetitive stimuli on out of domain consumption impatience. J Consumer Res34:649-656.

Mazur JE, Coe D (1987) Tests of transitivity in choices between fixed and variable reinforcer delays. J Exp Anal Behav 47:287-297. CrossRef Medline

Miedl SF, Peters J, Büchel C (2012) Altered neural reward representations in pathological gamblers revealed by delay and probability discounting. Arch Gen Psychiatry 69:177-186. CrossRef Medline

O’Doherty J, Dayan P, Schultz J, Deichmann R, Friston K, Dolan RJ (2004) Dissociable roles of ventral and dorsal striatum in instrumental conditioning. Science 304:452-454. CrossRef Medline

Oldfield RC (1971) The assessment and analysis of handedness: the Edinburgh inventory. Neuropsychologia 9:97-113. CrossRef Medline

Ostlund SB, Maidment NT (2012) Dopamine receptor blockade attenuates the general incentive motivational effects of noncontingently delivered rewards and reward-paired cues without affecting their ability to bias action selection. Neuropsychopharmacology 37:508-519. CrossRef Medline

Peters J, Büchel C (2009) Overlapping and distinct neural systems code for subjective value during intertemporal and risky decision making. J Neurosci 29:15727-15734. CrossRef Medline

Peters J, Büchel C (2010a) Episodic future thinking reduces reward delay discounting through an enhancement of prefrontal-mediotemporal interactions. Neuron 66:138-148. CrossRef Medline

Peters J, Büchel C (2010b) Neural representations of subjective reward value. Behav Brain Res 213:135-141. CrossRef Medline

Peters J, Bromberg U, Schneider S, Brassen S, Menz M, Banaschewski T, Conrod PJ, Flor H, Gallinat J, Garavan H, Heinz A, Itterman B, Lathrop M, Martinot JL, Paus T, Poline JB, Robbins TW, Rietschel M, Smolka M, Ströhle A, et al. (2011) Lower ventral striatal activation during reward anticipation in adolescent smokers. Am J Psychiatry 168:540-549. CrossRef Medline

Petry J (1996) Psychotherapie der Glücksspielsucht. Weinheim: Beltz/Psychologie Verlags Union.

Petry NM (2001a) Delay discounting of money and alcohol in actively using alcoholics, currently abstinent alcoholics, and controls. Psychopharmacology 154:243-250. CrossRef Medline

Petry NM (2001b) Pathological gamblers, with and without substance use disorders, discount delayed rewards at high rates. J Abnorm Psychol 110: 482-487. CrossRef Medline

Potenza MN (2008) The neurobiology of pathological gambling and drug addiction: an overview and new findings. Philos Trans R Soc Lond B Biol Sci 363:3181-3189. CrossRef Medline

Potenza MN, Steinberg MA, Skudlarski P, Fulbright RK, Lacadie CM, Wilber MK, Rounsaville BJ, Gore JC, Wexler BE (2003) Gambling urges in pathological gambling: a functional magnetic resonance imaging study. Arch Gen Psychiatry 60:828-836. CrossRef Medline

Reuter J, Raedler T, Rose M, Hand I, Gläscher J, Büchel C (2005) Pathological gambling is linked to reduced activation of the mesolimbic reward system. Nat Neurosci 8:147-148. CrossRef Medline

Robbins SJ, Ehrman RN (2004) The role of attentional bias in substance abuse. Behav Cogn Neurosci Rev 3:243-260. CrossRef Medline

Schott BH, Seidenbecher CI, Fenker DB, Lauer CJ, Bunzeck N, Bernstein HG, Tischmeyer W, Gundelfinger ED, Heinze HJ, Düzel E (2006) The dopaminergic midbrain participates in human episodic memory formation: evidence from genetic imaging. J Neurosci 26:1407-1417. CrossRef Medline

Schott BH, Minuzzi L, Krebs RM, Elmenhorst D, Lang M, Winz OH, Seiden- 
becher CI, Coenen HH, Heinze HJ, Zilles K, Düzel E, Bauer A (2008) Mesolimbic functional magnetic resonance imaging activations during reward anticipation correlate with reward-related ventral striatal dopamine release. J Neurosci 28:14311-14319. CrossRef Medline

Schwarz G (1978) Estimating the dimension of a model. Ann Statist 6:461464. CrossRef

Sescousse G, Barbalat G, Domenech P, Dreher JC (2013) Imbalance in the sensitivity to different types of rewards in pathological gambling. Brain 136:2527-2538. CrossRef Medline

Sheffer C, Mackillop J, McGeary J, Landes R, Carter L, Yi R, Jones B, Christensen D, Stitzer M, Jackson L, Bickel W (2012) Delay discounting, locus of control, and cognitive impulsiveness independently predict tobacco dependence treatment outcomes in a highly dependent, lower socioeconomic group of smokers. Am J Addict 21:221232. CrossRef Medline

van Holst RJ, Veltman DJ, van den Brink W, Goudriaan AE (2012) Right on cue? Striatal reactivity in problem gamblers. Biol Psychiatry 72:e23-e24. CrossRef Medline

Volkow ND, Wang GJ, Telang F, Fowler JS, Logan J, Childress AR, Jayne M, Ma Y, Wong C (2006) Cocaine cues and dopamine in dorsal striatum: mechanism of craving in cocaine addiction. J Neurosci 26:6583-6588. CrossRef Medline

Wilson M, Daly M (2004) Do pretty women inspire men to discount the future? Proc R Soc Lond B Biol Sci 271:S177-S179. CrossRef 